\title{
LENGUA Y MODELO DE ESTADO
}

MIGUEL A. APARICIO PÉREZ

Catedrático de Derecho Constitucional

Universidad de Barcelona 


\section{SUMARIO}

1. Observaciones generales. 2. Sobre la indeterminación del modelo de EstaDO. 3. SOBRE LA RELACIÓN ENTRE ESTRUCTURA SOCIO-INSTITUCIONAL, LENGUA Y MODElo de Estado en la realidad política y constitucional en España. 4. Sobre los DISTINTOS MODELOS LINGÜÍSTICOS EN EL DERECHO COMPARADO Y EN EL ÁMBITO INTERnacional. 5. Algunas propuestas para el debate. 


\title{
LENGUA Y MODELO DE ESTADO ICONFERENCIA IMPARTIDA EN LOS CURSOS DE VERANO DE EL ESCORIAL —UNIVERSIDAD COMPLUTENSE- EL DÍA 14 DE JULIO DE 1995) (*)
}

\author{
POR \\ MIGUEL A. APARICIO PÉREZ \\ Catedrático de Derecho Constitucional \\ Universidad de Barcelona
}

\section{OBSERVACIONES GENERALES}

Quiero iniciar esta intervención relatando una pequeña historia que yo he vivido en la Facultad de Derecho de la Universidad de Barcelona. Cuando hace diecisiete años se aprobó la Constitución española y, ya en el curso 1978-1979, se empezaron a constituir las primeras asociaciones universitarias de estudiantes, el panorama de sus reivindicaciones lingüísticas era, más o menos, el siguiente: la derecha nacionalista exigía un mayor impulso del catalán como idioma docente y discente $y$, es más, como centro nuclear de su programa universitario; la derecha españolista (los núcleos insertos en AP, sobre todo) insistía en la necesaria protección del castellano; la izquierda socialista y comunista proclamaba un sistema mixto de convivencia lingüística pero

(*) Las presentes reflexiones han sido extraídas del trabajo del autor sobre la constitucionalidad de la Ley de normalización lingüística en Cataluña. Aunque la redacción ha sido efectuada ex novo para esta circunstancia, lo cierto es que tanto la documentación utilizada como la mayor parte de sugerencias que aquí se contienen proceden de la mencionada aportación. 
apostando claramente por la promoción del idioma catalán. En estos momentos sólo puede verse un slogan en los pasquines de las paredes de la Facultad: «El bilingüismo es cultura». Estos pasquines los firma la ultraderechista y españolista AU (Agrupación Universitaria, de connotaciones claramente fascistas).

Este fenómeno evolutivo puede ser interpretado de diversas formas: como que el idioma catalán en cuanto vehículo de comunicación social y científica ha ganado la batalla y el castellano se encuentra en abierta retirada; o que la lengua en Cataluña ha dejado de ser un problema porque se ha alcanzado esa deseada "normalización", de la que luego hablaremos, o, en fin, se podría entender que ha existido un reparto entre grupos monolingüísticos que se hallan obligados a convivir al estilo quebecquiano (es decir, con territorios más o menos delimitados en los cuales existe una lengua hegemónica). $Y$, sin embargo, en mi opinión, ninguna de esa posibles interpretaciones $-y$ aun otras que hubiere- son ni del todo ciertas ni del todo inexactas. Y ello porque la realidad idiomática entremezcla elementos de muy variado y opuesto signo de la propia realidad social y de la realidad institucional. En estos días se comentaba en la prensa de Madrid (por el conocido periodista Justino Sinova) el libro de los profesores universitarios de Barcelona J. M. Solé y J. Villarroya titulado El catalán, una lengua asediada. Y se concluía el comentario crítico señalando: «Prefiero pensar que han querido hacer un trabajo histórico y que el tono encendido de algunas afirmaciones no es más que el reflejo de la tensión que alcanza este problema en Cataluña" (EI Mundo, 10 de julio de 1995, pág. 16). Tampoco deja de llevar razón el periodista pero, a la vez, tampoco la tiene.

El llamado problema de la lengua en Cataluña no lo es tanto; lo mismo que tampoco lo es tanto el llamado problema catalán. Ambos son objeto de comercio político diario en cualquiera de los bandos en que se utilice en interés propio, y son muchos bandos (y no sólo dos, como permanentemente se nos quiere hacer creer) quienes los utilizan. Lo que habría que preguntarse es por qué tanto la lengua catalana como la identidad nacional de Cataluña son sentidos como problema. Es más - y si se me permite-, ese sentimiento problemático reside tanto en el interior de Cataluña como en el resto de España, aunque, indudablemente, reside de forma muy distinta y con muy desemejantes connotaciones: lo que para unos es problema por el tópico "hecho diferencial" que se reclama, para otros lo es también porque ese mismo tópico no es reconocido; y así podríamos seguir hasta el infinito. 
Mas la cuestión no es ésa. La cuestión es si interesa - si nos interesa-saber de qué estamos hablando. Es decir, si interesa a alguien ponerse de acuerdo sobre determinadas realidades, tanto sociales, como políticas, como institucionales, que posean una naturaleza básica. $Y$ para ello hay que partir de algo tan primario como es el diseño del tipo o modelo de Estado que se desea, si es que se desea algún modelo definido de Estado. Porque, por todas las apariencias, valga la expresión vulgar, muy pocos quieren "mojarse" en ese terreno tan pantanoso. $Y$, sin embargo, es el punto necesario de partida, no sólo para entender esos denominados hechos diferenciales ( $y$ no hace falta acudir a ningún lingüista para comprobar su falta de contenido significante, puesto que no se dice cuál es el término de la comparación), sino para normalizar cada uno de los que puedan existir dentro de un cuadro de relaciones sociales y políticas previsibles por establecidas y aceptadas.

\section{SOBRE LA INDETERMINACIÓN DEL MODELO DE ESTADO}

Porque, en mi opinión, los problemas originales de España como Estado no residen ni en Cataluña ni en el País Vasco. Los problemas originales de España, en este ámbito, siguen residiendo en la falta de diseño coherente y consensuado de un tipo o modelo concreto de Estado que pueda cumplir una de sus razones de ser más importante: la integración de todos los ciudadanos y de todos los territorios sobre los que se ejerce la soberanía.

$Y$ en este ámbito los problemas de indefinición son múltiples. Unos de origen histórico, que no han sido superados: la tensión entre centralismo y sociedad heterogénea tanto desde el punto de vista de la tradición cultural como de la posesión de lenguas diversas o como, sobre todo, de la distinta articulación y contenido de sus clases sociales; las guerras civiles; la propia debilidad y artificialidad del aparato estatal; la tardía e inacabada revolución burguesa... y así un múltiple etcétera tan apasionante de analizar como con demasiada frecuencia olvidado. Otros, en cambio, perfectamente actuales: indefinición constitucional e indefinición de las fuerzas políticas.

Conviene detenerse en este último doble punto porque es donde quiero centrar el núcleo de mis reflexiones: existe una clara falta de concreción en la Constitución sobre el modelo de Estado que se pretende y existe una aún mayor falta de concreción sobre el mismo aspecto por parte de la generalidad de las fuerzas políticas. 
En efecto, en la Constitución el reparto territorial del poder político, como todo el mundo admite, no posee un diseño acabado. Es más, a mi juicio, lo único que diseña no es tanto un modelo más o menos completo como un contramodelo: un Estado no centralista ni centralizado. A partir de ahí - y deseo evitar descripciones bastante obvias sobre estos aspectos normativos - la Constitución reenvía la determinación del mismo a futuros consensos políticos a través de un doble mecanismo: los Estatutos de autonomía y las leyes marco, las leyes de transferencia y las leyes de delegación. Se plantea, pues, como un proyecto de futuro que, además, posee, por el mismo pronunciamiento constitucional, una peculiarisima condición: al existir esos mecanismos de traspaso de competencias estatales a las Comunidades Autónomas sin límite de tiempo, siempre se hallará abierta la posibilidad de modificar el panorama competencial de acuerdo con las coyunturas políticas. En último extremo: de acuerdo con que las fuerzas políticas nacionalistas acepten o no un determinado statu quo y una determinada aceptación del modelo de Estado en que se desenvuelven. $Y$ ello, como todo el mundo sabe, no parece próximo.

En este último sentido, el modelo constitucional de Estado, en su perspectiva de distribución territorial del poder, es un modelo que cabalga en tres indefiniciones permanentes: la de la distribución competencial, la diferenciación entre nacionalidades y regiones o, lo que es lo mismo, la aceptación del principio de desigualdad en el contenido del derecho a la autonomía (ex art. 2. de la CE) y -con especial trascendencia - la continua desconstitucionalización de ese modelo al dejarlo en manos de acuerdos políticos y formas normativas que deben actuar debajo de la Constitución.

La cuestión no sería especialmente grave si, por utilizar un lugar común, el clima político fuera propicio a ese tipo de desarrollo. Se puede decir -y es cierto- que el desarrollo del Estado de las Autonomías, una vez que se ha cerrado el mapa de las mismas y sus Estatutos, ha alcanzado unos perfiles propios y unas determinadas reglas de juego generalmente aceptadas sobre todo por la acción del Tribunal Constitucional en este campo. Pero este optimismo puede ser engañoso. Hace unos días el profesor Gumersindo Trujillo se lamentaba de la inexistencia entre nosotros de una teoría constitucional del Estado autonómico y yo me permití indicarle - y él asintió-que tal teoría no existía porque era imposible: no se puede teorizar sobre un concepto de Estado sobre el que no se tiene concepto. Se puede hacerlo técnicamente sobre los tipos de competencias, sobre las relaciones de inordenación, de colaboración, etc. - con el grave riesgo de que tales rela- 
ciones ni siquiera se hallen jurídicamente formalizadas-, sobre instituciones concretas, pero siempre se hará tomando modelos foráneos que poco o nada tienen que ver con nuestra realidad estatal.

$Y$ es que, dado nuestro sistema constitucional, que no pudo reflejar un acuerdo político del poder constituyente sobre el modelo de Estado, la misión les está entregada a las fuerzas políticas. Misión que rigurosamente ni han cumplido ni quieren cumplir por muy diferentes razones. En primer lugar, porque los modelos sobre los que operan son muy opuestos en sus líneas generales (de manera intuitiva aparecen desde federalismos dualistas, federalismos cooperativos, confederaciones o simplemente independentismos, todo ello regado con alguna que otra nostalgia del Estado centralista); en segundo lugar, porque las grandes fuerzas políticas de ámbito estatal -me refiero, como es obvio, al PSOE y al PP- no han realizado ningún esfuerzo positivo en este sentido; en tercero, porque las fuerzas nacionalistas del País Vasco y Cataluña esconden con gran cuidado cualquier compromiso de diseño de Estado, no se sabe bien - y posiblemente ellas tampoco- si porque defienden algo distinto a los principios constitucionales o porque en su falta de pronunciamiento encuentran una gran fuerza para la negociación política concreta; $y$, en último lugar, porque su acomodo en la indefinición evita plantear cuestiones trascendentes que, una vez más, pudiera dar lugar a una nueva confrontación civil.

Podrían enumerarse otras causas y otras explicaciones, pero parece bastante cierto que es éste el lugar en que nos encontramos. Y a partir de esta ausencia es donde surgen los inconvenientes en la convivencia social y grupal. $Y$ uno de ellos, desde luego y como señalaba al principio, es el que plantea el tema lingüístico que en un modelo acabado - por ejemplo, el suizo o, actualmente, el belga - no tendría mayores consecuencias pero que entre nosotros es fuente continua de conflictos.

3. SOBRE LA RELACIÓN ENTRE ESTRUCTURA SOCIOINSTITUCIONAL, LENGUA Y MODELO DE ESTADO EN LA REALIDAD POLITICA Y CONSTITUCIONAL ESPAÑOLA

\section{A) Un primer acercamiento}

Al cabo de diecisiete años de la vigencia de la Constitución no me deja de sorprender que el 15 de febrero del año pasado se planteara por la Sección Tercera de la Sala Tercera del Tribunal Supremo una 
cuestión de inconstitucionalidad sobre la Ley $7 / 1983$, de 18 de abril, de normalización lingüística en Cataluña. $Y$ no por el hecho en sí del planteamiento de una cuestión de inconstitucionalidad, sino por los planteamientos que en dicho auto se formulaban $y$, sobre todo, por la agresividad que se traslucía en sus fundamentos de derecho, que, para hacerse una idea, eran nada menos que veintidós. Así, en el cuarto se afirmaba que, a diferencia de lo mantenido por la Generalitat, si bien todos los ciudadanos tenían el deber de conocer el castellano, en aquellas Comunidades Autónomas donde exista además otra lengua oficial no tienen ninguna obligación de conocer la lengua cooficial distinta a la del castellano. Ello se repite y en ello se insiste en los fundamentos posteriores. No es mi intención entrar a polemizar ni sobre el contenido de dicho auto (aunque la verdad es que si me gustaría) ni siquiera sobre la Sentencia del Tribunal Constitucional de 23 de diciembre de 1994, que decidió que los preceptos de la ley impugnada eran constitucionales basándose, en mi parecer, en juicios de oportunidad, en una contradictoria concepción del Estado autonómico (como no podia ser menos) sobre la que tengo intención de trabajar en el inmediato futuro. Baste decir que, aunque mucho más extensos en su redacción, el número de fundamentos jurídicos de esta sentencia se acercaba al de los contenidos en el auto: veintiuno.

$Y$, sin embargo, la ley impugnada no sólo no tenía nada de inconstitucional en su texto (entendido como texto normativo), sino que, a mi parecer, se quedaba muy detrás de las posibilidades competenciales que en materia de enseñanza del y en catalán ofrecían tanto la Constitución como, especialmente, el Estatuto de Autonomía de Cataluña. De nuevo, ese exceso verbal y de papeleo no obedecía sino a una cuestión política no sólo mal resuelta sino que, en los términos actuales, resulta irresoluble.

\section{B) El planteamiento jurídico del problema}

Usualmente la utilización de la lengua o del idioma se viene considerando jurídicamente como uno de los derechos de la personalidad que encontrarían su apoyo constitucional no sólo en el artículo 3 , sino también en el artículo 10.1 de la Constitución. A mi juicio, ése es un mal planteamiento porque, inmediatamente, surge la constatación real de que unos ciudadanos tienen más derecho a su personalidad que otros. En efecto, si seguimos el razonamiento de la Sección Tercera de la Sa- 
la Tercera del Tribunal Supremo, los castellano-parlantes tienen derecho a la enseñanza en castellano en Cataluña, pero los catalanoparlantes no tienen derecho a la enseñanza en catalán en Asturias (pongamos por caso, para no introducir la mención a Madrid). Los derechos, en cualquier caso, se han de modular dentro del marco del Estado-Ordenamiento en que se reconocen y protegen y nunca ni por encima ni por debajo del mismo. Por eso y por mucha fibra que resulte afectada con el tema, la cuestión lingüística no se incardina en el interior del sistema de derechos subjetivos (que a estos efectos no existe), sino en el sistema de regulación constitucional (política) del Estado-Ordenamiento.

Bueno será, por tanto, analizar más de cerca el conflicto al que nos referiamos en el inicio de este apartado. En el fondo nos hallamos ante la cuestión del reparto del poder político entre distintos centros de atribución y de la naturaleza constitucional $-\mathrm{y}$, como hemos visto, infraconstitucional- de este tipo de reparto: es decir, de la naturaleza del Estado que nos hallamos dispuestos a compartir o, en su caso, a hacer efectivo. En nuestro ámbito, pues $-y$ así lo creo-, nos hallamos de nuevo ante un posible problema de la delimitación de competencias entre Estado y Comunidad Autónoma, donde se cruzan dos títulos competenciales diferentes: la enseñanza como competencia vertical y la lengua como competencia horizontal.

Por eso y para seguir las pautas previstas se hace necesario volver al conflicto sobre normativa lingüística a que se ha hecho referencia desde la perspectiva del reparto competencial y no desde la perspectiva de los derechos subjetivos que, en todo caso, son límite pero no contenido de las competencias de las instituciones públicas.

\section{C) La competencia de normalización lingüística}

EI Preámbulo de la Constitución declara su voluntad de proteger a todos los españoles y los pueblos de España en el ejercicio de los derechos humanos, sus culturas y tradiciones, lenguas e instituciones. Esto es desarrollado de diversas formas, como la del art. 3 del Estatuto de Autonomía de Cataluña.

De la interpretación sistemática de los fines expresados en el Preámbulo y de este conjunto de preceptos se desprenden una serie de constataciones iniciales. Tal vez la más evidente, por repetida, sea la 
del reconocimiento de la realidad plurinacional de España, cualquiera que sea el significado que se confiera al término, y desde luego de la realidad plurilingüe; la segunda, la de que nos hallamos ante un reconocimiento "protector" y de "fomento", no sólo de esa realidad plurilingüe en cuanto factor "cultural", sino también en cuanto elemento estructural convivencial de las entidades territoriales en las que la misma se produce; la tercera, que a estas proclamaciones constitucionales se les ligan una serie de garantías institucionales: la autonomía política territorial, en cuanto marco de acción y de poder propio, y el enunciado de una serie de competencias, explícitas e implícitas, para llevarla a cabo.

Y la cuarta, que en ningún momento la Constitución contenga principio alguno, antes al contrario, que impida a una Comunidad Autónoma con lengua propia no sólo fomentar (pues lo ordena), sino incluso generalizar en sus ámbitos competenciales, con la consiguiente carga de exigibilidad, el uso de dicha lengua.

Sin entrar, por el momento, en el análisis de la diferenciación del conocido tema de las garantías institucionales y los derechos fundamentales, procede señalar, sin embargo, que nuestra Constitución determina el contenido de tales garantías institucionales ly el contenido de las mismas no es otra cosa, cuando se refieren a instituciones públicas, que la adjudicación de competencias) a través de dos mecanismos: el reparto competencial, por un lado, y la remisión a los Estatutos de Autonomía, por otro.

El problema que en esta delimitación se nos presenta es el de averiguar si, en ese marco constitucional de la autonomía política, la Generalidad de Cataluña: a) tiene competencia sobre la "materia» lengua catalana; b) de qué tipo de competencia se trata, y c) qué ámbitos de proyección posee.

Se ha argumentado en diversos recursos constitucionales, usualmente por el Abogado del Estado (vid. ad ex. STC 83/1986, de 26 de junio), que la materia lingüística no constituye un título competencial sustantivo. Puede ello indicar sólo dos cosas: o que se trata de un título competencial adjetivo a otro, por conexión, o que no existe atribución competencial alguna, salvo en lo que se refiere el art. 148, 1, 17.. CE a la materia del fomento de la enseñanza de la lengua. Incluso algunas sentencias del propio Tribunal Constitucional podrian llevar a semejante conclusión. Así, la STC 69/1988, de 19 de abril, indicaba en su fundamento jurídico $3 .^{\circ}$ que "debemos recordar que el art. 3.3 de su Estatuto, más que enunciado de una norma competencial expresa un 
mandato -STC 82/1986, de 26 de junio-o un deber - STC 6/1982, de 22 de febrero- que impone a las instituciones y órganos autonómicos para que, con ocasión de sus competencias propias, procuren marcar los objetivos marcados en aquel precepto estatutario, estando, por tanto, en presencia, no de una competencia en sentido propio, sino de un compromiso de promoción de la normalización lingüística, cuyo fundamento primero se encuentra en el art. 3.3 de la Constitución y que, con cobertura en la citada regla del Estatuto, se desarrolla en la Ley 7/1983, de 18 de abril, del Parlamento de Cataluña». Y añadía inmediatamente que "este mandato de normalización del uso de las lenguas oficiales en el territorio catalán no confiere, pues, competencia especifica alguna a la Comunidad Autónoma frente al Estado..."; esta misma doctrina se vuelve a repetir en la STC 80/1988, de 22 de abril, aunque con mayores matizaciones: en este último supuesto (sobre, igualmente, cuestiones de "etiquetaje") ya se admite, de forma literal, que la Comunidad Autónoma ostenta competencia sobre la lengua. En concreto, su fundamento jurídico $3 .^{\circ}$ señala que "con independencia, asimismo, de que la Comunidad Autónoma ostente competencia (art. 27.20 de su Estatuto) para la promoción de la lengua gallega, pues este título competencial, por más genérico e indeterminado que el relativo a la udefensa del consumidor y el usuario", no es el que aquí se ha de considerar actuado". Es de observar que en la primera de las sentencias que se acaban de citar se niega la cualidad de título competencial; en la segunda, en cambio, sobre el mismo objeto, se la reconoce, aunque con ese carácter de ser "genérico e indeterminado".

Pese a ello, ni ésa es la doctrina dominante en el Tribunal Constitucional, ni puede apoyarse en sólidos criterios. El defender que no es un título competencial comporta el vaciar de contenido el mandato constitucional del art. 3.2 y su concreción del art. 3 del Estatuto de Autonomía; el defender que es un título "genérico", o no quiere decir nada (que, simplemente, no es tal título) o sólo quiere decir que únicamente opera cuando se encuentra adherido a otro concreto, con lo cual el problema se desvía al ámbito competencial material de ese título específico: el determinar si, dentro de él, se encuentra algún tipo de competencia en el ámbito lingüístico. Cualquiera de estas dos opciones conduciría a declarar la inconstitucionalidad material del art. 3.3 del Estatuto de Autonomía de Cataluña, cuando ordena que "la Generalidad garantizará el uso normal y oficial de los dos idiomas, adoptará las medidas necesarias para asegurar su conocimiento y creará las condiciones que permitan alcanzar su plena igualdad en lo que se refiere a los derechos y deberes de los ciudadanos de Cataluñan, y de los correspondientes preceptos de los demás Estatutos de Autonomía que esta- 
blecen semejantes previsiones. En la primera de ellas, porque sería irracional imponer un deber sin competencias para cumplirlo; en la segunda, por ser inútil o, en el mejor de los casos, redundante por innecesario.

En efecto, es evidente que la Generalidad no puede garantizar el "uso normal y oficial de los dos idiomas" si no es materia propia o compartida; que no puede adoptar medida alguna para asegurar su conocimiento, si ello no le confiere un determinado título competencial sustantivo, es decir, material; con lo que, por último, difícilmente se puede conseguir la igualdad idiomática en un campo cuya posibilidad de dirección "autónoma» se le deniega.

Por eso - y ésta es la que consideramos doctrina dominante en el Tribunal Constitucional- la STC 82/1986, de 26 de junio, recaida en el recurso de inconstitucionalidad interpuesto contra determinados preceptos de la Ley 10/1982, de 24 de noviembre, del Parlamento vasco, sobre el uso del euskera, venía a admitir con gran claridad la presencia de un auténtico título competencial en materia lingüística. Se abordaba el problema en términos explícitos cuando en su fundamento jurídico cuarto se indicaba:

"Sentadas estas premisas, es preciso abordar la cuestión de las competencias en materia lingüística, planteada sucesivamente por el Abogado del Estado y la representación del Gobierno Vasco."

Es decir, que el Tribunal Constitucional admite "expresis verbis" que nos hallamos ante un problema competencial. Cuestión que, en el mismo fundamento juridico, se dejaba aún más clara al indicar, también, también que:

"Interpretar el art. 149.1.1, con el alcance que le otorga el Abogado del Estado, equivaldría a vaciar de contenido las competencias lingüísticas asumidas por las Comunidades Autónomas según sus Estatutos de acuerdo con lo dispuesto en el art. 3.2 de la Constitución".

$Y$, por si quedara alguna duda en su calificación jurídica como materia competencial, añadía de forma casi inmediata:

"De cuanto llevamos dicho en este fundamento se desprende que la competencia que al Estado otorga el art. 149.1.1 de la Constitución no se opone a la que para las Comunidades Autónomas se deriva del artículo 3.2 de la Constitución y de sus respectivos Estatutos de Autonomía..." 
Por otro lado, quizás la síntesis interpretativa más clarificadora de la propia doctrina del Tribunal Constitucional se encuentre en la STC $74 / 1989$, de 24 de abril, en cuyo fundamento jurídico $3 .^{\circ}$ se decía textualmente:

«Recordando ahora lo dicho en la STC 82/1986, de 26 de junio, a propósito del Estatuto de Autonomía del País Vasco - similar al que aquí se analiza- es de señalar que del juego del art. 3.2 de la Constitución y del art. 3. ${ }^{\circ}$ del Estatuto de Autonomía de Cataluña -en el que han de verse contenidos "mandatos a las correspondientes instituciones autonómicas para regular la cooficialidad de la lengua propia"- deriva la competencia en materia lingüística de la Generalidad, que resulta de esta forma habilitada para determinar el alcance de la cooficialidad, por lo que "no cabe hablar de actuación fuera de la esfera competencial de la Comunidad Autónoma", cuando ésta prevé consecuencias lógicas que resultan de la declaración de cooficialidad."

Llegados a este punto, parece evidente, como no podía ser menos, que la materia lingüística es competencia funcional de las Comunidades Autónomas que cuentan con lengua propia diferente de la general del Estado. Sobre el punto de la distinta calificación de una y otra (ambas oficiales en el territorio de la Comunidad por mandato de la Constitución pero sin idéntico tratamiento, aunque sólo fuera, en la mera razón de perogrullo, porque son lenguas distintas que, además, se hallan en situación desigual) procede posiblemente el adentrarse en la segunda cuestión que planteábamos más arriba: admitida la naturaleza competencial de la materia, habremos de analizar de qué tipo de competencia se trata.

$Y$ también en este aspecto, de la misma doctrina del Tribunal Constitucional se puede extraer una conclusión bastante aproximada: la lengua propia de la Comunidad, en su relación de cooficialidad con el castellano, es competencia, si no exclusiva, sí predominante de la Comunidad Autónoma respecto a la propia de que pudiera disponer el Estado central. Se trataría así de un a modo de competencia compartida entre ambas instancias cuando la materia "lengua" se conectara con otra materia compartida (el contenido de la enseñanza, por ejemplo); pero funcionaría como competencia exclusiva cuando esa misma materia "lengua propia" pudiera ser objeto de tratamiento independiente. No otra cosa puede derivarse de la STC 82/1986: la afirmación de que "no cabe entender que este título competencial habilite al Estado para regular, con carácter general, siquiera en sus aspectos básicos, 
la cooficialidad de las lenguas españolas distintas al castellano y su consiguiente utilización por los poderes públicos o el derecho al uso de otras lenguas españolas oficiales por los particulares" (F.J. 4) no viene a indicar más que, esa materia, concebida así, es competencia exclusiva de la Comunidad Autónoma correspondiente. En el mismo sentido se pronunció la STC 74/1989, de 24 de abril, anteriormente mencionada.

No cabe, sin embargo, olvidar que, sentada la naturaleza competencial de la materia "lengua propia", ésta también posee una proyección "horizontal» por cuanto se adhiere a títulos competenciales verticales. Dicho en términos ejemplificadores, la materia lengua presenta esa perspectiva horizontal porque se proyecta en cualquier tipo de relación humana regulada (e, incluso, no regulada) por el derecho; $y$, como consecuencia, con mayor razón aún, cobra cuerpo específico cuando se adhiere a ámbitos competenciales de aquella Comunidad Autónoma que, valga la redundancia, posee "lengua propia». El problema, entonces, se circunscribe a determinar lo que, en términos sociológicos, podría denominarse el conflicto "interlingüístico»; o, expresado en términos más adecuados a nuestro ordenamiento constitucional, a determinar las líneas divisorias competenciales entre Estado central y Comunidades Autónomas en aquellos territorios en los que coexisten dos lenguas cooficiales.

De inmediato hay que advertir que, en el parecer de quien suscribe, esa línea divisoria en materia de lengua posee dos centros competenciales compartidos, pero en desigual posición: por utilizar la expresión acuñada anteriormente, el Estado central posee competencia predominante en materia de lengua castellana, mientras que la Generalidad de Cataluña posee competencia predominante en materia de lengua catalana. La articulación entre ambos núcleos y ambas posiciones competenciales no puede realizarse sino por la vía de la complementariedad y la coordinación: vía que únicamente es transitable si se integran en un mismo proyecto (que es a lo que reconducen los principios de unidad y solidaridad) los fines expresos fijados por la Constitución y por el bloque de la constitucionalidad. $Y$ esos fines vienen determinados no sólo por el concepto de "cooficialidad", sino también por los antes mencionados de fomento y protección (términos éstos en los que no entramos por hallarse suficientemente desarrollados en las "alegaciones» que en su día efectuó el Gabinete Jurídico Central ante la Providencia de la Sección de la Sala 3. ${ }^{\text {a }}$ del Tribunal Supremo en que se anunciaba la intención de interponer la cuestión de inconstitucionalidad ya referida). 
Con ello, damos contestación al tercer aspecto que se planteaba: el ámbito de proyección competencial. El principio de que se parte no sólo es el, ya mencionado, de la doble oficialidad, sino también el de conseguir la igualdad entre las lenguas. La complicada redacción del artículo 3.3 del Estatuto de Autonomía de Cataluña en su último enunciado ("y creará las condiciones que permitan alcanzar su plena igualdad en lo que se refiere a los derechos y deberes de los ciudadanos de Cataluña»), en relación con el art. 3.2 de la Constitución ("las demás lenguas españolas serán también oficiales en sus respectivas Comunidades Autónomas, de acuerdo con sus Estatutos") cobra un significado perfectamente identificable: los ciudadanos de Cataluña —según el expreso fin del Estatuto- tienen, en una progresiva línea tendencial y dinámica, los mismos derechos y deberes respecto de los dos idiomas: el catalán y el castellano. Este último, por imperativo de la Constitución que, como es obvio, el Estatuto respeta; aquél, por imperativo directo del Estatuto, habilitado expresa y ampliamente por la Constitución. Repárese, no obstante, en que se está hablando de los mismos "derechos y deberes»; con ello, el Estatuto introduce, mediante la habilitación constitucional del art. 3.2 de la Constitución, la paridad tendencial del tratamiento jurídico de ambos idiomas; o, en términos de referencia contractual sinalagmática, la igualdad de derechos y obligaciones de las partes que, en este caso y por seguir con la metáfora iusprivatista, son el Estado central y la Generalidad de Cataluña, por un lado, y los ciudadanos castellano-parlantes y catalano-parlantes, por otro, y todos ellos entre sí. Con lo que, por adelantar otra de las conclusiones, se está estableciendo un auténtico deber estatutario de conocimiento del catalán en parecidos términos a los que fija el art. 3.1 de la Constitución en lo que se refiere al idioma castellano.

Al llegar aquí, el resultado argumental no puede ser otro que el de recoger las propias especificaciones del bloque de la constitucionalidad a la luz de la jurisprudencia constitucional. $Y$ son que: a) la lengua catalana es materia competencial; b) la competencia le corresponde a la Generalitat de Cataluña, con carácter, si no exclusivo, sí predominante; c) ese ámbito competencial es finalista en cuanto habilita a la Generalidad a conseguir la igualdad de los derechos y deberes lingüísticos de los ciudadanos de Cataluña respecto de los dos idiomas conjuntamente considerados.

Pese a todo, y para terminar este apartado, convendría efectuar algunas consideraciones comparativas entre determinados preceptos "promocionales" o "finalistas" contenidos en la Constitución Española y en el Estatuto de Autonomía de Cataluña. Tal vez la comparación 
más relevante sea la que surge entre el art. 9.2 de la Constitución sobre la promoción de la libertad y la igualdad "reales" y el art. 3, 1 y 2, del Estatuto, sobre la promoción, en condiciones de igualdad, de la lengua catalana. Porque, efectivamente, en lo que se refiere al art. 9.2 de la Constitución, la jurisprudencia constitucional ha sentado tres líneas delimitadoras de su campo de actuación: 1.a) no confiere habilitación competencial alguna (STC 25/1981, de 24 de julio); 2. a) no crea derechos subjetivos (STC 39/1986, de 31 de marzo); 3.a) no opera como límite específico a la actuación de los poderes públicos (STC 98/1985, de 29 de julio).

Dejando aparte comentarios laterales sobre tal delimitación jurisprudencial, lo cierto es que tanto la estructura como el contenido de las dos normas "promocionales" referidas poseen diferencias sustanciales. Mientras el mandato constitucional, por su propia esencia, es generalísimo, la norma estatutaria, por idéntica cualidad, impone una mayor concreción; cuando la Constitución fija un fin abierto a situaciones múltiples y contradictorias, el Estatuto establece y ordena un resultado específico; mientras, en fin, el texto constitucional no habla en ningún momento de derechos subjetivos, el estatutario determina de manera explícita el "alcanzar su plena igualdad en lo que se refiere a los derechos y deberes de los ciudadanos de Cataluñan. Por lo tanto, el objeto de promoción "lengua", por parte de la Generalidad de Cataluña, se liga a auténticos derechos y deberes subjetivos de los ciudadanos que, por definición, en el ámbito del derecho público, no tienen otra contrapartida que el de las competencias y obligaciones de los poderes públicos encargados de satisfacerlos; es decir, de las instituciones de la Generalidad de Cataluña, tal como determina el Estatuto de Autonomía.

\section{LOS MODELOS EDUCATIVOS LINGÜÍSTICOS EN EL DERECHO COMPARADO Y EN LA JURISPRUDENCIA INTERNACIONAL}

Avanzando algo más en las constataciones previas, nos corresponde ahora observar qué asideros de nuestro ámbito jurídico cultural nos permiten enmarcar ese modelo al que se acaba de hacer referencia.

Comenzando por lo más cercano, conviene recordar que la Convención de salvaguardia de los derechos fundamentales del hombre $y$ las libertades fundamentales, en su protocolo adicional, ratificado por 
España el 18 de marzo de 1982 ( $y$, formando parte de nuestro ordenamiento jurídico, con, además, la especial fuerza que confiere a este tipo de convenios el art. 10.2 de nuestra Constitución), señala en su artículo 2 que:

"A nadie se puede negar el derecho a la instrucción. El Estado, en el ejercicio de las funciones que asumirá en el campo de la educación y la enseñanza, respetará el derecho de los padres a asegurar esta educación y esta enseñanza conforme a sus convicciones filosóficas y religiosas."

A partir de esta proclamación, el Tribunal Europeo de Derechos Humanos ha tenido ocasión de conocer algunos casos sobre el régimen lingüístico educativo por su posible colisión con tal precepto. Así, uno de los más conocidos fue el «relativo a algunos aspectos del régimen lingüístico de la enseñanza en Bélgica", resuelto por la Sentencia de dicho Tribunal de 23 de julio de 1968. Los demandantes mantenían que "las convicciones filosóficas" incluían necesariamente las preferencias culturales y lingüísticas de los padres a la hora de que sus hijos recibieran la oportuna enseñanza. La decisión del Tribunal fue unánime sobre este punto: "El Tribunal hace notar que el artículo 14 (del Convenio Europeo), incluso en su conexión con el art. 2 del Protocolo, no tiene por efecto el garantizar a los hijos o a sus padres el derecho a una instrucción impartida en la lengua de su elección (...). Interpretar estos dos artículos como si reconocieran a toda persona dependiente de la jurisdicción de un Estado el derecho a ser instruido en la lengua de su elección, conduciría a resultados absurdos, ya que todos podrían asi reivindicar una instrucción impartida en cualquier lengua, en cualquiera de los territorios de las Partes Contratantes". Para volver a precisar posteriormente (Caso Campbell y Cosans, Sentencia de $25 \mathrm{de}$ febrero de 1982) que por convicciones filosóficas ha de entenderse "las convicciones merecedoras de respeto en una sociedad democrática que no son incompatibles con la dignidad humana $y$, además, no se oponen al derecho fundamental del niño a la instrucción".

$Y$ es que el TEDH distingue entre el derecho a la educación, como obligación prioritaria a cargo de los padres, y el derecho a la instrucción como derecho a recibir enseñanza, y cuya garantía, en principio, corresponde a los poderes públicos. De acuerdo con esta distinción, el TEDH ha fijado una serie de contenidos de este derecho a través de diversas sentencias - la ya citada de 23 de julio de 1968 y la de 7 de diciembre de 1976, principalmente - que, en resumen, serían los siguientes: el derecho de acceso a los establecimientos escolares exis- 
tentes; la posibilidad de obtener mediante el reconocimiento oficial de los estudios realizados un beneficio de la enseñanza recibida, de acuerdo con las reglas vigentes en cada Estado; que el Estado reglamente la enseñanza y planifique los estudios. No existe, en cambio, obligación de los Estados para crear centros de enseñanza ni para subvencionar la enseñanza, pues ésta es una cuestión de política interna, aunque el TEDH prohíbe que en una misma escuela se impartan enseñanzas subvencionadas y no subvencionadas. En tales supuestos "las convicciones filosóficas y religiosas de los padres" operan como límites a las funciones del Estado, aunque, según se ha señalado, no recogen la facultad de opción lingüística.

Tampoco aparece el derecho de elección lingüística en materia educativa en la "Declaración Universal de los Derechos del Niño", aprobada por la Asamblea General de la ONU el 20 de noviembre de 1959. Al hablar de los derechos educativos del menor, el principio 7 se limita textualmente a señalar lo que sigue:

«El niño tiene derecho a recibir educación, que será gratuita y obligatoria al menos en su etapa elemental. Se le dará una educación que favorezca su cultura general y le permita, en condiciones de igualdad de oportunidades, desarrollar sus actitudes y su juicio individual, su sentido de la responsabilidad moral y social y convertirse en un miembro útil a la sociedad.»

E igualmente ocurre con el tratamiento de ese tema por la Convención sobre los Derechos del Niño, adoptada por la Asamblea General de la ONU el 20 de noviembre de 1989, cuando en su art. 30 establece el derecho de libertad de utilizar personalmente el propio idioma, y el art. $29 \mathrm{cl}$, al establecer un deber genérico de inculcar el respeto al idioma propio.

Idéntica cuestión sucede con la «Convención sobre la lucha contra la discriminación en la esfera de la educación", adoptada por la Conferencia General de la Unesco el 14 de diciembre de 1960. El principio II, 1 (igual que ocurre con otros textos internacionales) prohíbe la discriminación por razón de lengua, pero, en cambio, no reputa como discriminatoria la educación separada por razón de lengua, siempre y cuando la asistencia a los centros separados sea facultativa (principio I, 2, b). Por el contrario, se reconocen derechos a las minorías nacionales:

"Procede reconocer a los miembros de las minorías nacionales el derecho a ejercer las actividades educativas que les sean propias, 
incluyendo el establecimiento y mantenimiento de escuela y, según la política educativa de cada Estado, el uso y la enseñanza de la propia lengua."

Este derecho se somete a determinadas condiciones, pero, en cualquier caso, no es relevante para el caso que nos ocupa porque no impone obligaciones positivas para el Estado.

En cuanto, por último, a la Declaración Universal de los Derechos del Hombre, no se introduce más que la prohibición de discriminación por razón de lengua (art. 1) y, al hablar en su art. 26 del derecho a la educación, no se mencionan para nada los derechos lingüísticos, señalándose tan sólo que «los padres tienen, con prioridad, derecho a escoger la clase de educación de sus hijos".

Si éste es el panorama general de la jurisprudencia del Tribunal Europeo de los Derechos del Hombre y de las Convenciones y Declaraciones internacionales, en el ámbito del derecho positivo comparado, como no podia ser menos, las soluciones educativo-lingüísticas adoptan las formas más diversas: el régimen de monolingüismo, el bilingüismo perfecto, el bilingüismo separado o el plurilingüismo en sus múltiples modalidades. En los Estados Unidos, por ejemplo, se combina tanto el monolingüismo como el bilingüismo, aunque prácticamente en todas las Constituciones de los Estados miembros se admiten determinadas excepciones o supuestos de flexibilización de tal regla: así la Constitución de California de 1983 señala que el inglés es la primera lengua de enseñanza en todas las escuelas y que el Estado tiene como política el asegurar que todos los alumnos de las escuelas dominen la lengua inglesa; añade, sin embargo, que "a condición de que la enseñanza bilingüe sea dispensada en aquellas situaciones en que se juzgue beneficiosa para los alumnos, ésta se autoriza en la medida en que no perturbe el programa regular de formación en lengua inglesa de los alumnos". En la de lowa (Constitución de 1983-84) se mantiene ese mismo sistema, previendo, no obstante, ayudas específicas a los alumnos no anglófonos. Por su parte, la de Nuevo México exige a los profesores una formación bilingüe, en inglés y en español, para enseñar a los alumnos hispano-hablantes en las escuelas públicas, aunque especifica que "la Legislatura es también responsable de dotar de medios y métodos apropiados para facilitar la enseñanza de la lengua inglesa y de otras materias a estos mismos alumnos" (art. 12). No faltan los Estados que reconocen el derecho a la enseñanza en la lengua materna: así, Lituania (Constitución de 1990), Perú (en la ya derogada de 1980) para las comunidades indígenas, como también sucede en Brasil (Constitu- 
ción de 1988) y, más matizadamente, Canadá (art. 23). La complejidad aumenta en el caso, como nuevo ejemplo, de Filipinas (Constitución de 1987), Estado en el que se distinguen dos lenguas oficiales (el filipino y el inglés), diversas lenguas regionales "oficiales auxiliares a la enseñanza" y lenguas a promocionar facultativamente como el español y el árabe.

Lo mismo sucede con los territorios que poseen una cierta autonomía política, en que también la diversidad es notable: en las Islas Feröe se enseña conjuntamente el feröe y el danés; en Groenlandia, el groenlandés y el danés. En cambio, en la provincia de Aland (Finlandia) no se enseña más que el sueco; en Calabria se promocionan las lenguas griega y albanesa para las poblaciones de este origen; en el Trentino-Alto Adigio se establece un régimen de separación lingüística según la procedencia del alumno de un grupo lingüístico determinado (italiano, alemán o ladino). Y así sucesivamente.

No existe, por lo tanto, un modelo educativo dominante ni en los Estados ni en los territorios dotados de cierta autonomía política. Por eso procede que volvamos a nuestras observaciones anteriores sobre el concreto caso que nos ocupa y que nos deben llevar a las conclusiones finales, en el curso del posible debate que, a continuación, y de forma directa, consigamos desarrollar. 